\title{
Active Vibration Control of Container Cranes against Earthquake by the Use of LMI Based Mixed $H_{2} / H_{\infty}$ State-Feedback Controller
}

\author{
C. Oktay Azeloglu and Ahmet Sagirli \\ Department of Mechanical Engineering, Yildiz Technical University, Istanbul, Turkey \\ Correspondence should be addressed to C. Oktay Azeloglu; azeloglu@yildiz.edu.tr
}

Received 19 August 2014; Accepted 5 January 2015

Academic Editor: Longjun Dong

Copyright (C) 2015 C. O. Azeloglu and A. Sagirli. This is an open access article distributed under the Creative Commons Attribution License, which permits unrestricted use, distribution, and reproduction in any medium, provided the original work is properly cited.

\begin{abstract}
This paper studies the design of a linear matrix inequality (LMI) based mixed $H_{2} / H_{\infty}$ state-feedback controller for vibration attenuation problem of seismic-excited container cranes. In order to show effectiveness of the designed controller, a six-degreeof-freedom container crane structural system is modeled using a spring-mass-damper subsystem. The system is then simulated against the real ground motion of El Centro and Northridge earthquakes. Finally, the time history of the crane parts displacements, accelerations, control forces, and frequency responses of both uncontrolled and controlled cases are presented. Additionally, the performance of the designed controller is also compared with a nominal state-feedback $H_{\infty}$ controller performance. Simulations of the designed controller show better seismic performance than a nominal state-feedback $H_{\infty}$ controller. Simulation results show that the designed controller is all effective in reducing vibration amplitudes of crane parts.
\end{abstract}

\section{Introduction}

In the recent years, earthquakes have caused much more loss of life and financial damage compared to those which occurred in previous centuries. Cranes are also affected by seismic movements. Cranes damaged in earthquakes cause loss of life together with economic losses. Moreover, cranes damaged on strategic points such as harbors and railways cause failure in logistic activities.

The importance of the earthquake induced destructive effects on cranes was understood in the late 1990s because large capacity cranes were not so common before that. With the rapid increase in import and export rates all around the world, large scale cranes were needed more than ever and as a result of that larger harbours use larger capacity cranes today. Another reason of this phenomenon was that there were no sufficient experiences related with the behaviour of cranes under earthquake loads, but 1995 Kobe Earthquake clearly exposed the destructive effects of earthquake motions on cranes (Figure 1) [1]. During Kobe Earthquake, many cranes were damaged and collapsed which highlighted the importance of improving the seismic performance of cranes. Studies related with this improvement is being carried on since 1995.

Some of the experiences about dynamic loading on cranes aim to understand the behaviour of cranes under seismic loading while some of them aim to suggest solutions to this problem. The first step on the process of understanding the dynamic behaviour of crane structures under earthquake loads is to create a scaled physical model of the crane and subject the physical model to shake table tests. Horizontal loads make the earthquakes destructive so physical model of the crane was subjected to uniaxial horizontal loading through the critical axis [2-4].

In literature, there are studies about active seismic control for crane structures. For example, Sagirli et al. [5] performed active vibration control studies to decrease the structural vibrations on gantry cranes. A five-degree-of-freedom nonlinear mathematical model which was developed for the gantry cranes and proved by shake table tests in the previous study (Sagirli and Azeloglu [6]) is used and a self-tuning fuzzy logic controller (STFLC) was designed as a control 


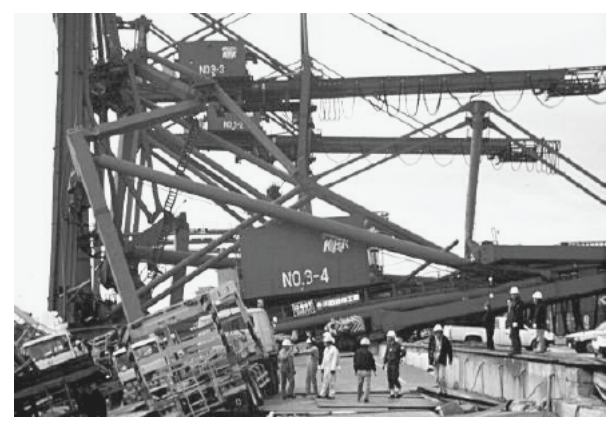

FIgURE 1: Collapsed cranes at Kobe Earthquake.

algorithm in the studies. The results obtained from simulation studies show that active vibration control can be successfully performed on gantry cranes.

Active vibration control has been widely used in many successful engineering applications and has demonstrated significant achievements and the results of studies in literature also show that active vibration control has a great potential in cranes for suppressing earthquake induced vibration [5]. It is clear that reducing seismic vibrations in crane structures and therefore the need for a design of more seismically safe cranes is an important topic on this area of research. Both active and passive control methods can be used to solve this problem. It is stated in related literature that active control methods are much more efficient when compared to passive methods. Therefore, in this paper, an active vibration control method is used to reduce seismic vibrations on cranes.

Active vibration control is one of the important branches of control theory and application [7]. However, one important issue of active vibration control is the existence of time-delay phenomenon [8-10]. In active structural control process, unavoidable time-delay may appear especially in control channel which mainly results from online data acquisition from long distance sensors at different location of the structure, computing the control forces, transmitting data and signals to actuator, and applying control forces to the structure. Due to time-delay in control input, unsynchronized control forces are applied to the structural system and this may cause some amount of degradation in control efficiency or even instability of system [11, 12]. Apart from time-delay, one of the main sources of instability is the actuator saturation phenomenon for the active vibration control problem of the mechanical systems [10, 13]. Due to the stochastic nature of seismic and wind loadings, it is conceivable that the required control force may exceed the capacity of the actuator, resulting in actuator saturation in structural control. Actuator saturation may lead to serious deterioration in the performance of the closed-loop system and may also lead to instability [14]. Another important issue in active vibration control of mechanical systems is uncertainties [15]. Because of the modeling errors, variation in material properties, and changing disturbance excitations, the description of structures inevitably contains uncertainties in different natures and levels. Since these uncertainties can affect both the stability and performance of control systems, many robust control methods are offered for the active control of structural systems $[16,17]$. This paper is a basic study on reducing structural vibration of cranes against seismic effects. Now then authors will also study algorithm including time-delay, actuator saturation, and uncertainties to control structural vibration of cranes originating from seismic effects.

In this study, LMI based mixed $\mathrm{H}_{2} / \mathrm{H}_{\infty}$ state-feedback controller has been designed to reduce of container crane system against earthquake. As known, $\mathrm{H}_{2}$ control gives more suitable performance on system transient behaviors; on the other hand, $H_{\infty}$ control design is mainly concerned with frequency domain performance and does not guarantee good transient behaviors for the closed-loop system. To obtain desired frequency and transient response performance, $\mathrm{H}_{2}$ and $H_{\infty}$ controller objectives have combined as a mixed control problem by the use of LMIs. A six-degree-of-freedom crane system subject to seismic excitations is used to illustrate the effectiveness of the approach through simulations. Additionally, the performance of the designed controller is also compared with a nominal state-feedback $H_{\infty}$ controller performance. Simulation results, obtained by using real timehistory data of El Centro and Northridge earthquakes, show that the proposed controller is very effective in reducing vibration amplitudes of crane parts.

The rest of the paper is organized as follows: Mathematical model of the crane is introduced in Section 2. The design of controller is presented in Section 3. Simulation results are demonstrated and discussed in Section 4. Finally, Section 5 concludes the paper.

\section{Mathematical Model of the Container Crane}

Researchers studied the multi-degree-of-freedom dynamic models which effectively reveals the dynamics of the system for active control applications of the cranes subjected to earthquake. In Sagirli and Azeloglu [6], a five-degree-offreedom nonlinear mathematical model of gantry crane is developed for active control studies and a comparison based on shake table tests is provided. Results obtained from mathematical model match the results obtained from the shake table model. Azeloglu et al. [18] developed a six-degree-offreedom nonlinear mathematical model of container crane to compare the shake table tests results. Physical model consists of inclusion of the foundation system and the payload. In this study, dynamics of the soil is also integrated to the developed mathematical model and earthquake motions are applied horizontally along the boom uniaxial. Results obtained from mathematical model match the results obtained from the shake table model. Azeloglu et al. [19] developed a fourdegree-of-freedom mathematical model of container crane to compare the shake table tests results. It is shown that all the developed mathematical models can be used as a crane model in active vibration control studies in order to decrease the structural vibrations on cranes. In this paper, a six-degreeof-freedom mathematical model which was developed for 


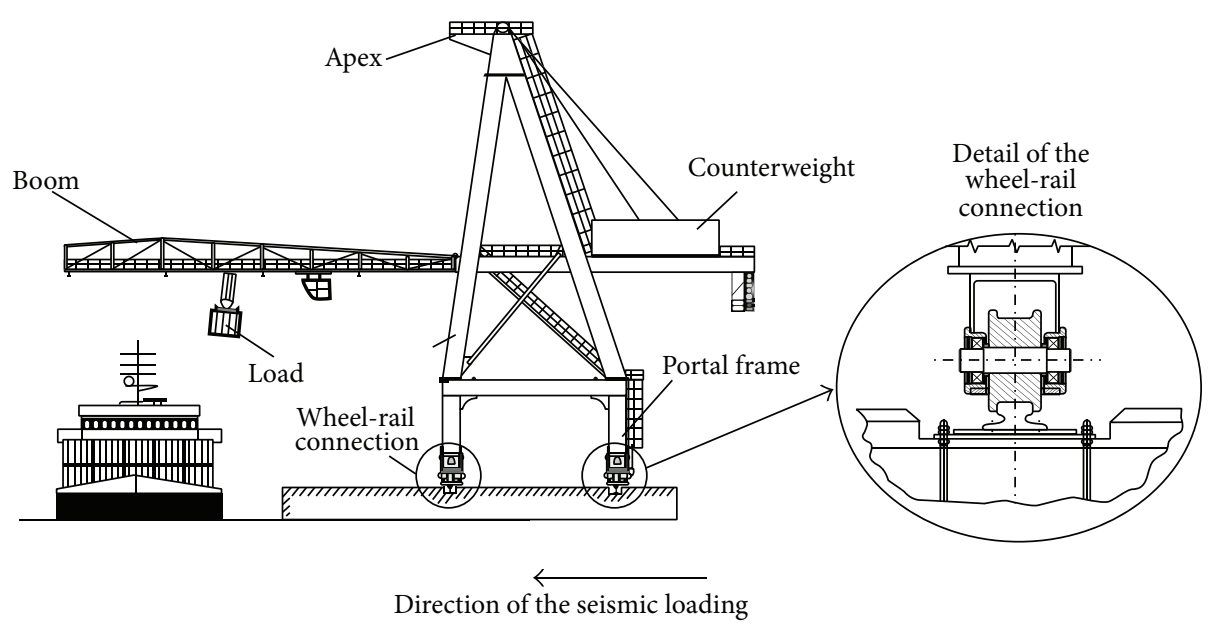

FIGURE 2: Schematic model of the container crane with the direction of seismic loading.

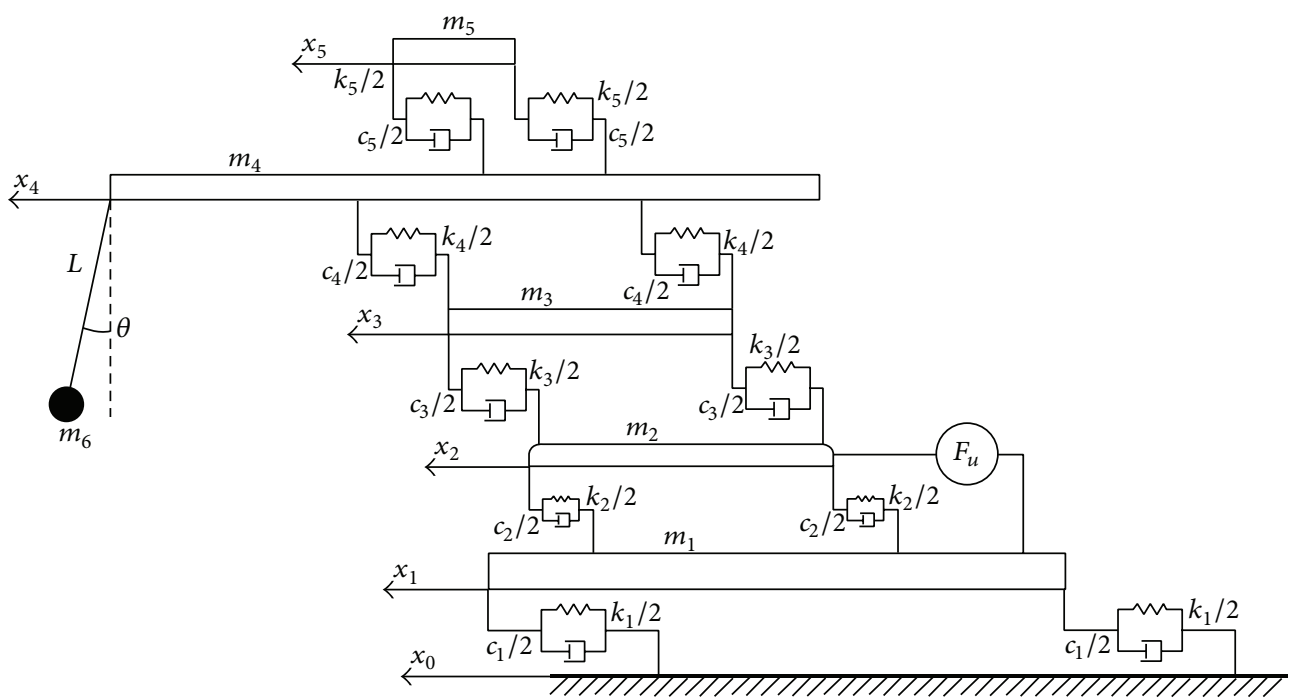

Figure 3: Dynamic model of the crane under seismic loading.

the container cranes and proved by shake table tests in the previous study (Azeloglu et al. [18]) is used.

The mathematical model of a six-degree-of-freedom container crane structural system which is modeled by using spring-mass-damper subsystems is developed. Since the destructive effect of earthquakes is a result of horizontal vibrations, only the degrees of freedom on horizontal directions have been assumed to be occurring $[18,19]$. The mathematical model also includes the dynamics of soil and a wheel-rail connection. Kobayashi et al. [20] show that a wheel-rail connection in cranes can be degraded to a spring and a damping element. So the wheel-rail connection in this study is included in the dynamic model with a spring and a damping element. However, an active control device (actuator), which supplies energy to suppress vibrations, is assumed to be installed between the container quay and wheel mechanism.
Schematic model of the container crane with the direction of seismic loading is represented in Figure 2. Figure 3 represents the dynamic model, where $m_{1}, m_{2}, m_{3}, m_{4}, m_{5}$, and $m_{6}$ represent the masses of container quay, wheel mechanism, portal beams, boom, apex, and payload, respectively, $k_{1}$ and $c_{1}$ are the stiffness of the soil and damping, $k_{2}$ is the stiffness of the wheel-rail connection, $k_{3}, k_{4}$, and $k_{5}$ are stiffness coefficients of the portal frame, $c_{2}$ is the damping of the wheelrail connection, $c_{3}, c_{4}$, and $c_{5}$ are damping coefficients of the portal frame, $L$ is the rope length, and $g$ is the gravitational acceleration. $x_{0}$ is the earthquake induced ground motion disturbance imposing on the crane structure, and $x_{1}, x_{2}, x_{3}$, $x_{4}, x_{5}$, and $\theta$ are the displacements of the related parts of the structure. The system parameters of a container crane are presented in the Appendix.

The mathematical model includes the following assumptions: (i) The degrees of freedom of the system are horizontal. 
(ii) The dynamic effects on the boom are uniaxial. (iii) The uniaxially effects of the earthquake motions along the boom are perpendicular to the rails. (iv) The distributed loads in the model are considered as point masses lumped at the center of mass of the corresponding element. (v) The rope is rigid and massless. (vi) The payload swing is planar. (vii) The stiffness and the damping effects of the soil along the boom are considered in the dynamic model. (viii) The stiffness and the damping effects of the wheel-rail connection along the boom are considered in the dynamic model. (ix) Lateral spaces in the wheel-rail connection are ignored. (x) An actuator is installed between the $x_{1}$ and the $x_{2}$.

Using the well known Lagrange method, the equation of motion of a container crane system having on actuator delay and which is subject to external disturbance can be obtained as follows:

$$
M_{s} \ddot{x}(t)+C_{s} \dot{x}(t)+K_{s} x(t)=F_{u} u(t)+E_{w} w(t) .
$$

Here, $x(t)=\left[\begin{array}{llllll}x_{1}(t) & x_{2}(t) & x_{3}(t) & x_{4}(t) & x_{5}(t) & \theta(t)\end{array}\right]^{T}$ is the displacement state vector of the container crane structure, $u(t)$ is the control force, $F \in \Re^{n \times m_{u}}$ gives the location of the controller, $w(t) \in W_{\delta}$ is the energy bounded disturbance input, and $E \in \mathfrak{R}^{m_{w}}$ is a matrix that weights the disturbances. Finally, $M_{s}, C_{s}, K_{s} \in \Re^{n \times n}$ are the mass, damping, and stiffness matrices of the crane structure, respectively. Then it is straightforward to obtain system matrices as follows:

$$
\begin{aligned}
& M_{s}=\left[\begin{array}{cccccc}
m_{1} & 0 & 0 & 0 & 0 & 0 \\
0 & m_{2} & 0 & 0 & 0 & 0 \\
0 & 0 & m_{3} & 0 & 0 & 0 \\
0 & 0 & 0 & m_{4}+m_{6} & 0 & m_{6} L \cos \theta \\
0 & 0 & 0 & 0 & m_{5} & 0 \\
0 & 0 & 0 & m_{6} L \cos \theta & 0 & m_{6} L^{2}
\end{array}\right], \\
& C_{s}=\left[\begin{array}{cccccc}
c_{1}+c_{2} & -c_{2} & 0 & 0 & 0 & 0 \\
-c_{2} & c_{2}+c_{3} & -c_{3} & 0 & 0 & 0 \\
0 & -c_{3} & c_{3}+c_{4} & -c_{4} & 0 & 0 \\
0 & 0 & -c_{4} & c_{4}+c_{5} & -c_{5} & 0 \\
0 & 0 & 0 & -c_{5} & c_{5} & 0 \\
0 & 0 & 0 & 0 & 0 & 0
\end{array}\right], \\
& K_{s}=\left[\begin{array}{cccccc}
k_{1}+k_{2} & -k_{2} & 0 & 0 & 0 & 0 \\
-k_{2} & k_{2}+k_{3} & -k_{3} & 0 & 0 & 0 \\
0 & -k_{3} & k_{3}+k_{4} & -k_{4} & 0 & 0 \\
0 & 0 & -k_{4} & k_{4}+k_{5} & -k_{5} & 0 \\
0 & 0 & 0 & -k_{5} & k_{5} & 0 \\
0 & 0 & 0 & 0 & 0 & m_{6} g L \sin \theta
\end{array}\right] .
\end{aligned}
$$

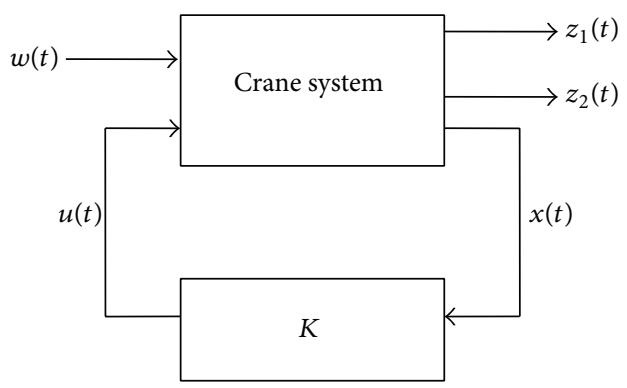

FIGURE 4: Block diagram of designed state-feedback control system.

\section{Controller Design}

3.1. LMI Based Mixed $\mathrm{H}_{2} / \mathrm{H}_{\infty}$ State-Feedback Controller Design. Francis [21] and Doyle et al. [22] developed statespace formulas that solved a standard optimal $H_{\infty}$ problem using Riccati equation thus making a significant breakthrough in optimal $H_{\infty}$ control. Chilali et al. [23] and Gahinet and Apkarian [24] applied formulations of the $H_{2}$ and $H_{\infty}$ control problem in terms of LMI which allow computational effectiveness and systematic design of robust controllers. $H_{\infty}$ control depends on minimizing the infinitive norm of transfer function matrix which is written from controlled output to disturbance input in order to avoid the disturbance input to affect the system. Therefore, $H_{\infty}$ control is very suitable control algorithm for the structural systems which are under effect of disturbance inputs with unknown magnitude as earthquakes. On the other hand, $H_{\infty}$ control design is mainly concerned with frequency domain performance and does not guarantee good transient behaviors for the closed-loop system. $\mathrm{H}_{2}$ control gives more suitable performance on system transient behaviors. In this study to obtain desired frequency and transient response performance, $H_{\infty}$ and $H_{2}$ controller objectives have combined as a mixed control problem by the use of LMIs. The block diagram of designed state-feedback control system is shown in Figure 4. Here, structural model is considered as linear time invariant (LTI) model.

The state-space representation of the system is given by

$$
\begin{gathered}
\dot{x}=A x+B_{1} w+B_{2} u, \\
z_{1}=C_{1} x+D_{11} w+D_{12} u, \\
z_{2}=C_{2} x+D_{21} w+D_{22} u,
\end{gathered}
$$

where $x \in \mathfrak{R}^{n}$ is the state vector, $z_{1}, z_{2} \in \mathfrak{R}^{n_{z}}$ are the controlled output, and $w \in \mathfrak{R}^{n_{w}}$ is the disturbance input. $u \in \mathfrak{R}^{n_{u}}$ is the control input vector. The control input is considered as linear function of the state; that is, $u=K x$ where, $(K \in$ $\left.\mathfrak{R}^{n_{u} \times n}\right)$ is the state-feedback gain. The closed-loop system can be written as follows:

$$
\begin{gathered}
\dot{x}=\left(A+B_{2} K\right) x+B_{1} w, \\
z_{1}=\left(C_{1}+D_{12} K\right) x+D_{11} w \\
z_{2}=\left(C_{2}+D_{22} K\right) x+D_{21} w .
\end{gathered}
$$


Suppose $T z_{1} w$ and $T z_{2} w$ denote the closed-loop transfer functions, respectively, from disturbance $(w)$ to measurements $\left(z_{1}\right.$ and $\left.z_{2}\right)$. The multiobjective state-feedback $H_{2} / H_{\infty}$ control may be described as follows. Find a state-feedback control law $u=K x$ such that it minimizes $\left\|T z_{2} w\right\|_{2}$ subject to $\left\|T z_{1} w\right\|_{\infty}<\gamma$. In order to find a state-feedback control law, $H_{2}$ and $H_{\infty}$ designed objectives have been separately derived by LMIs. These two constraints can be combined into one design expression as mixed $\mathrm{H}_{2} / \mathrm{H}_{\infty}$ controller. The Bounded Real Lemma plays a central role to obtain the $H_{\infty}$ constraint. There exists a quadratic Lyapunov function $V(x)=x^{T} P x, P>0, \gamma>0$ such that for all $t$. If we assume the initial conditions are zero, the Hamiltonian of the system (8) becomes

$$
\dot{V}(x)+z_{1}^{T} z_{1}-\gamma^{2} w^{T} w<0
$$

and this Hamiltonian must be negative definite for all $x$ and $w$. The following equation can be obtained by substituting (4) into (5):

$$
\begin{aligned}
& {\left[\left(A+B_{2} K\right) x+B_{1} w\right]^{T} P x+x^{T} P\left[\left(A+B_{2} K\right) x+B_{1} w\right]} \\
& \quad+\left[\left(C_{1}+D_{12} K\right) x+D_{11} w\right]^{T}\left[\left(C_{1}+D_{12} K\right) x+D_{11} w\right] \\
& \quad-\gamma^{2} w^{T} w<0 .
\end{aligned}
$$

Arranging inequality (6) the following matrix inequality can be obtained as

$$
\left[\begin{array}{cc}
\left(\left(A+B_{2} K\right)^{T} P+P\left(A+B_{2} K\right)+\left(C_{1}+D_{12} K\right)^{T}\left(C_{1}+D_{12} K\right)\right) & P B_{1}+\left(C_{1}+D_{12} K\right)^{T} D_{11} \\
B_{1}{ }^{T} P+D_{11}{ }^{T}\left(C_{1}+D_{12} K\right) & -\gamma^{2} I+D_{11}{ }^{T} D_{11}
\end{array}\right]<0 .
$$

Inequality (7) takes the final form using the Schur complement. Suppose $P$ and $R$ are symmetric matrices. The condition

$$
\left[\begin{array}{ll}
P & S \\
S^{T} & R
\end{array}\right]>0
$$

is equivalent to

$$
P>0, \quad P-S R^{-1} S^{T}>0
$$

and postmultiplying (7) by $P^{-1}$ and using Schur complement, inequality (10) can be written as

$$
\begin{aligned}
& P^{-1}\left(A+B_{2} K\right)^{T}+\left(A+B_{2} K\right) P^{-1} \\
& \quad+P^{-1}\left(C_{1}+D_{12} K\right)^{T}\left(C_{1}+D_{12} K\right) P^{-1} \\
& \quad-\left(B_{1}+P^{-1}\left(C_{1}+D_{12} K\right)^{T} D_{11}\right) \\
& \quad \cdot\left(-\gamma^{2} I+D_{11} D_{11}^{T}\right)^{-1}\left(B_{1}^{T}+D_{11}^{T}\left(C_{1}+D_{12} K\right) P^{-1}\right)<0 .
\end{aligned}
$$

Applying the variable change $X_{\infty}=P^{-1}$ the following LMIs can be obtained:

$$
\begin{aligned}
& {\left[\begin{array}{cc}
\left(\left(A+B_{2} K\right) X_{\infty}+X_{\infty}\left(A+B_{2} K\right)^{T} X_{\infty}\left(C_{1}+D_{12} K\right)^{T}\left(C_{1}+D_{12} K\right) X_{\infty}\right) & B_{1}+X_{\infty}\left(C_{1}+D_{12} K\right)^{T} D_{11} \\
B_{1}{ }^{T}+D_{11}{ }^{T}\left(C_{1}+D_{12} K\right) X_{\infty} & -\gamma^{2} I+D_{11}{ }^{T} D_{11}
\end{array}\right]<0,} \\
& {\left[\begin{array}{cc}
\left(A+B_{2} K\right) X_{\infty}+X_{\infty}\left(A+B_{2} K\right)^{T} & B_{1} \\
B_{1}{ }^{T} & -\gamma I
\end{array}\right]+\frac{1}{\gamma}\left[\begin{array}{c}
X_{\infty}\left(C_{1}+D_{12} K\right)^{T} \\
D_{11}{ }^{T}
\end{array}\right]\left[\left(C_{1}+D_{12} K\right) X_{\infty} \quad D_{11}\right]<0 .}
\end{aligned}
$$


By the use of Schur complement again, the following inequality can be obtained as $H_{\infty}$ constraint of the closed-loop system (4) for $X_{\infty}>0$,

$$
\left[\begin{array}{ccc}
\left(A+B_{2} K\right) X_{\infty}+X_{\infty}\left(A+B_{2} K\right)^{T} & B_{1} & X_{\infty}\left(C_{1}+D_{12} K\right)^{T} \\
B_{1}{ }^{T} & -\gamma I & D_{11}{ }^{T} \\
\left(C_{1}+D_{12} K\right) X_{\infty} & D_{11} & -\gamma I
\end{array}\right]<0 .
$$

The optimal $\mathrm{H}_{2}$ controller can be obtained by searching the minimum $\eta$ which satisfies the above mentioned LMIs for $X_{2}=X_{2}{ }^{T}$ and $Q=Q^{T}$. Note that the $H_{2}$ norm of $\left\|T z_{2} w\right\|_{2}^{2}$ is finite if and only if $D_{21}=0$ :

$$
\begin{gathered}
\left(A+B_{2} K\right) X_{2}+X_{2}\left(A+B_{2} K\right)^{T}+B_{1} B_{1}^{T}<0, \\
{\left[\begin{array}{cc}
Q & \left(C_{2}+D_{22} K\right) X_{2} \\
X_{2}\left(C_{2}+D_{22} K\right)^{T} & X_{2}
\end{array}\right]>0}
\end{gathered}
$$

$$
\operatorname{Trace}(Q)<\eta \text {. }
$$

The main objective of this paper is to determine a statefeedback mixed $H_{2} / H_{\infty}$ controller gain. To obtain proposed controller structure, it is convenient to combine the $\mathrm{H}_{2}$ and $H_{\infty}$ designed objectives to form a mixed $H_{2} / H_{\infty}$ controller. Here, $\mathrm{H}_{2} / \mathrm{H}_{\infty}$ control problem is to minimize the $\mathrm{H}_{2}$ norm of the $T z_{2} w$ overall state-feedback gains $K$ such that it also satisfies the $H_{\infty}$ norm constraints [25]. Conversely, inequalities (12), (13), and (14) are not convex because of the $K X_{2}$ and $K X_{\infty}$ terms. To overcome this problem a common Lyapunov matrix such that $X=X_{2}=X_{\infty}$ with the change of the variable $W=K X$ is used. In this way, the multiobjective $\mathrm{H}_{2} / \mathrm{H}_{\infty}$ control using $\mathrm{H}_{2}$ and $H_{\infty}$ performance constraints can be obtained as follows:

$$
\begin{gathered}
{\left[\begin{array}{ccc}
A X+X A^{T}+B_{2} W+W^{T} B_{2}{ }^{T} & B_{1} & X C_{1}{ }^{T}+W^{T} D_{12}{ }^{T} \\
B_{1}{ }^{T} & -\gamma I & D_{11}{ }^{T} \\
C_{1} X+D_{12} W & D_{11} & -\gamma I
\end{array}\right]<0} \\
{\left[\begin{array}{cc}
Q & C_{2} X+D_{22} W \\
X C_{2}{ }^{T}+W^{T} D_{22}{ }^{T} & X
\end{array}\right]>0,} \\
\operatorname{Trace}(Q)<\eta .
\end{gathered}
$$

After finding a solution $(X, Q, W)$ of this mixed control problem, the optimal state-feedback gain for the closed-loop system is obtained as

$$
K=W X^{-1}
$$

All the simulations and computations are done using Matlab with Simulink. For the solution of the resulting LMIs, YALMIP parser and LMILAB solver are used [26]. The controller gain is obtained as

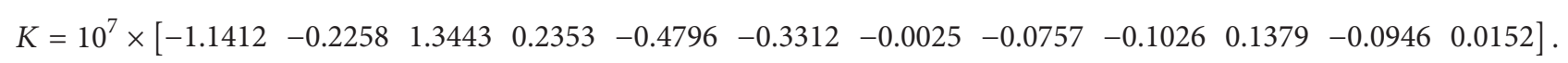

For brevity, from this point onwards we will henceforth denote this controller as Controller 1. Displacements and velocities of the earthquake ground motion are used as exogenous signal and the control law is selected to be full state-feedback controller. All state-space matrices of the closed-loop system are presented in the Appendix.

3.2. Nominal State-Feedback $H_{\infty}$ Controller Design. In order to compare the performance of designed controller with nominal $H_{\infty}$ state-feedback controller, in the following sequel, the design equations for a static state-feedback $H_{\infty}$ controller have been obtained [27].

Let us consider a nominal linear time invariant system given by

$$
\begin{gathered}
\dot{x}(t)=A x(t)+B_{1} w(t)+B_{2} u(t), \\
z_{1}(t)=C_{1} x(t)+D_{11} w(t)+D_{12} u(t),
\end{gathered}
$$

where $x(t) \in \mathfrak{R}^{n}$ is the state vector. $u(t) \in \mathfrak{R}^{m_{u}}$ is the control input, $w(t) \in \mathfrak{R}^{m_{w}}$ is the disturbance input, and $z_{1}(t) \in \mathfrak{R}^{p}$ is the controlled output vector. Suppose that the control input is linear function of the state; that is,

$$
u(t)=K x(t)
$$

where $K \in \Re^{m_{u} \times n}$ is the state-feedback gain. The closed-loop system is given by

$$
\begin{gathered}
\dot{x}(t)=\left(A+B_{2} K\right) x(t)+B_{1} w(t), \\
z_{1}(t)=\left(C_{1}+D_{12}\right) x(t)+D_{11} w(t) .
\end{gathered}
$$

The optimal nominal $H_{\infty}$ state-feedback controller can be obtained by searching minimum allowable $\gamma$, which satisfies 


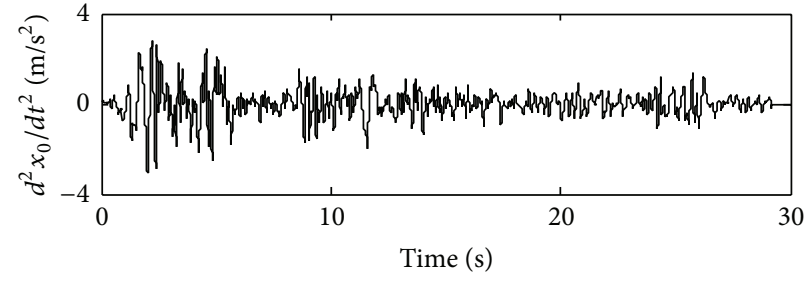

(a)

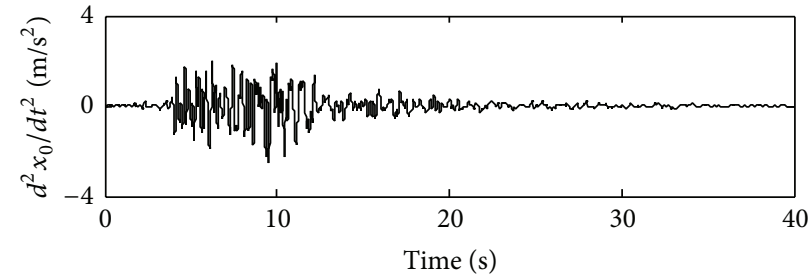

(b)

Figure 5: (a) El Centro and (b) Northridge earthquake excitations input to the structure.

the following LMI for $X=X^{T}>0$ and a matrix $L$ in appropriate dimension:

$$
\left[\begin{array}{ccc}
A X+X A^{T}+B_{2} L+L^{T} B_{2}^{T} & B_{1} & X C_{1}{ }^{T}+L^{T} D_{12}^{T} \\
B_{1}^{T} & -\gamma I & D_{11}^{T} \\
C_{1} X+D_{12} L & D_{11} & -\gamma I
\end{array}\right]<0 .
$$

If there exists a feasible solution to the optimization problem (22), the optimal $H_{\infty}$ state-feedback controller can be constructed as $u(t)=L X^{-1} x(t)$. The controller gain is obtained as

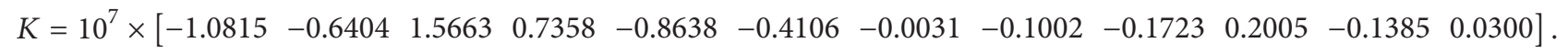

For brevity, we will henceforth denote this controller as Controller 2.

\section{Simulation Study}

In this section, simulation study is carried out in order to illustrate the effectiveness of the proposed controller in reducing the effect of earthquakes on crane structures. The El Centro and Northridge earthquake motions which were used as an input of seismic excitation are shown in Figure 5 [28].

Figure 6 indicates displacement and acceleration of the time responses of the crane parts, respectively, for both controlled and uncontrolled cases against El Centro earthquake. As shown in Figure 6, vibration amplitudes of the crane parts are decreased successfully with designed controller.

Performance of designed controller is checked against different disturbances using ground motion of the Northridge earthquake (Figure 7). It is desired that the controller remains stable and effective when the crane structure is subjected to different disturbances. As it can be seen, from the Figure 7, satisfactory vibration suppression is achieved under different earthquake ground motion by proposed controller. Figure 8 demonstrates the variation of control forces obtained in El Centro and Northridge earthquakes, respectively.

Figure 9 shows the frequency responses of the crane boom displacements and accelerations, respectively, for both controlled and uncontrolled cases. Since the system has six degrees of freedom, there are six resonance frequency points at $0.19,0.44,0.87,1.21,1.97$, and $2.61 \mathrm{~Hz}$. As expected, the upper curves belong to the uncontrolled system. When the response plots of the crane structural system with uncontrolled and Controller 1 cases are compared, a superior improvement in the attenuation of the resonance values is observed with the proposed controller. It is well known that the first mode is the most dangerous for crane structures during an earthquake [29]. However, it is obvious that this mode is successfully suppressed by proposed controller.

It can be seen from the figures that the designed controller suppresses structural vibration effectively being independent from the characteristics of disturbed load. Due to the fact that boom has the biggest mass and the most devastating effect in the crane structure, boom vibrations are particularly examined and the results are quite satisfactory.

The performance of the designed controller (Controller 1) is compared with a nominal state-feedback $H_{\infty}$ controller (Controller 2) for the crane boom in Figures 10 and 11. As shown in Figures 10 and 11, displacements and accelerations of the crane boom are minimized successfully using Controller 1. As compared with Controller 2 cases, displacements and accelerations of the system are suppressed better. Figure 12 also shows the frequency responses of the crane boom Controller 1 and Controller 2 cases.

\section{Conclusion}

In this study, LMI based mixed $\mathrm{H}_{2} / \mathrm{H}_{\infty}$ state-feedback controller has been designed to reduce container crane system against earthquake. As known, $H_{2}$ control gives more suitable performance on system transient behaviors; on the other hand, $H_{\infty}$ control design is mainly concerned with 

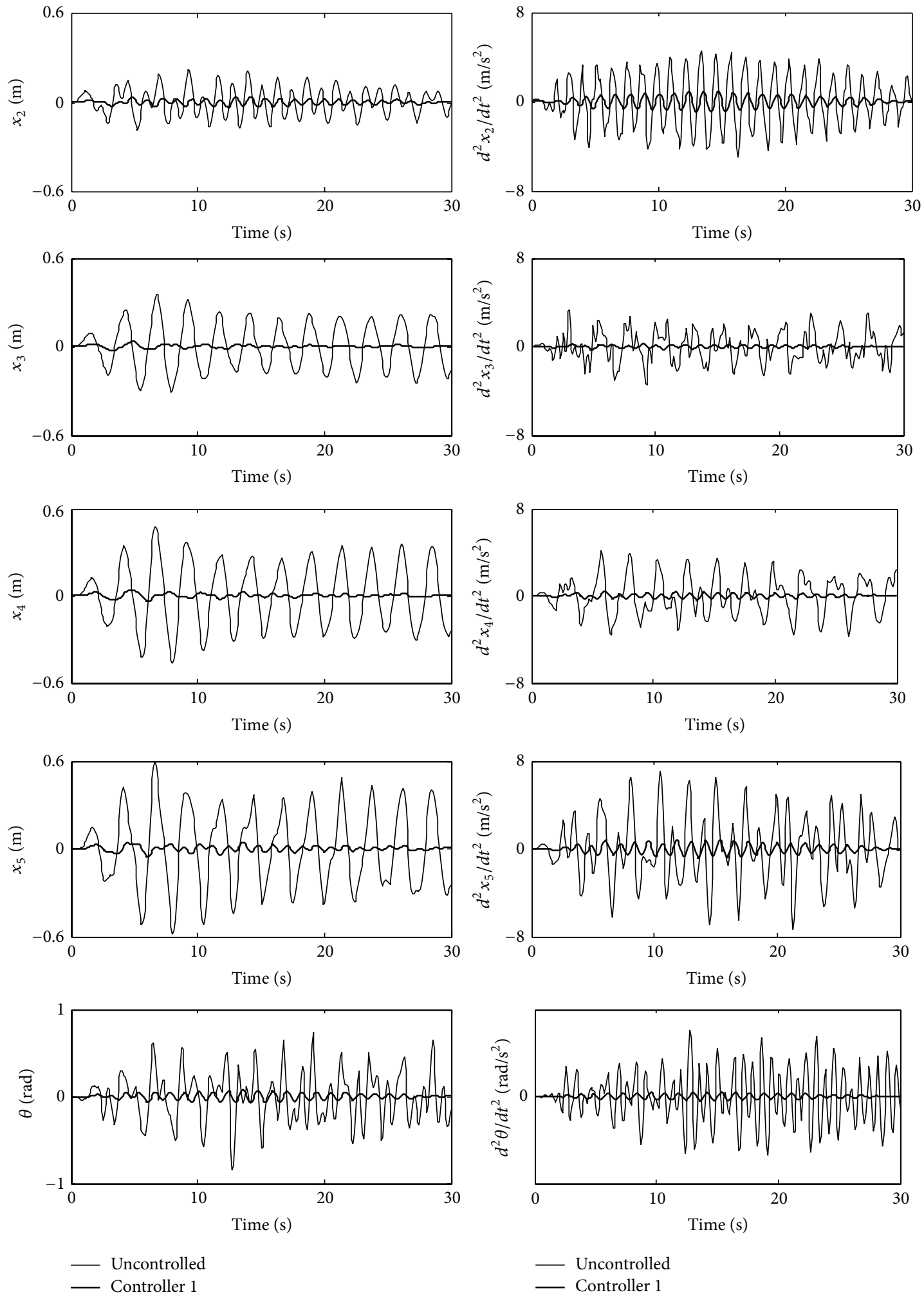

FIgURE 6: Time responses of the container crane against El Centro earthquake. 

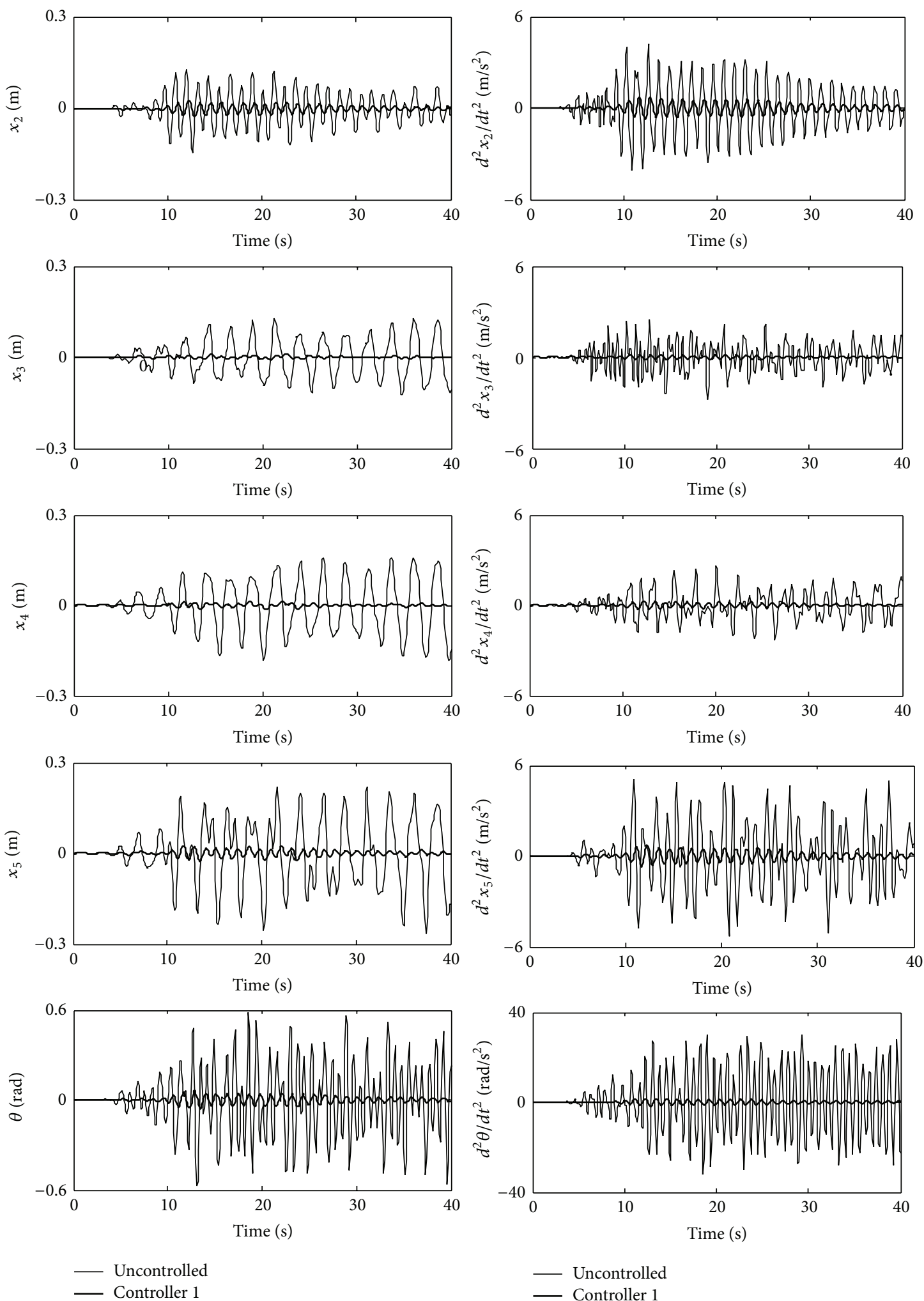

FIGURE 7: Time responses of the container crane against Northridge earthquake. 


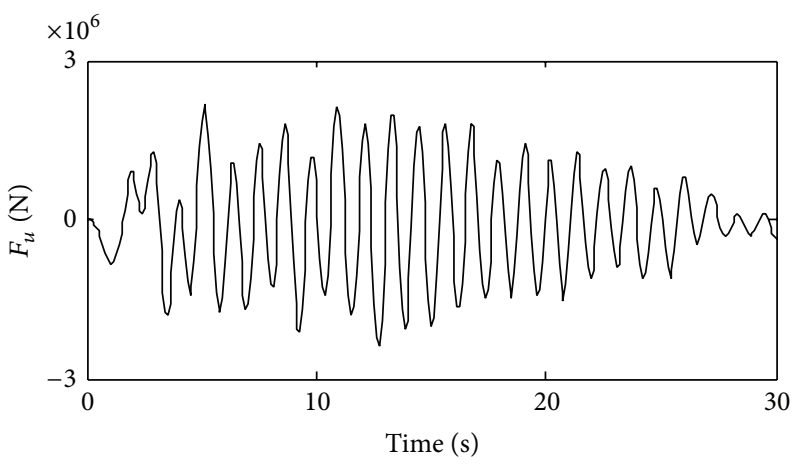

(a)

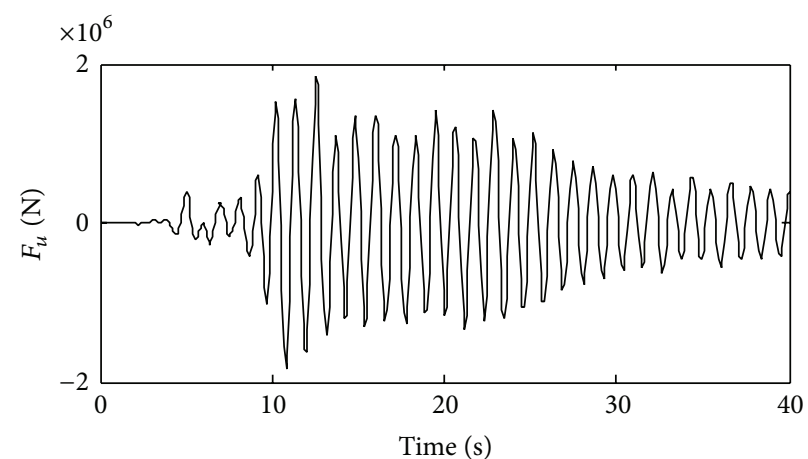

(b)

FIgURE 8: Time histories of the applied control forces for (a) El Centro and (b) Northridge earthquakes.

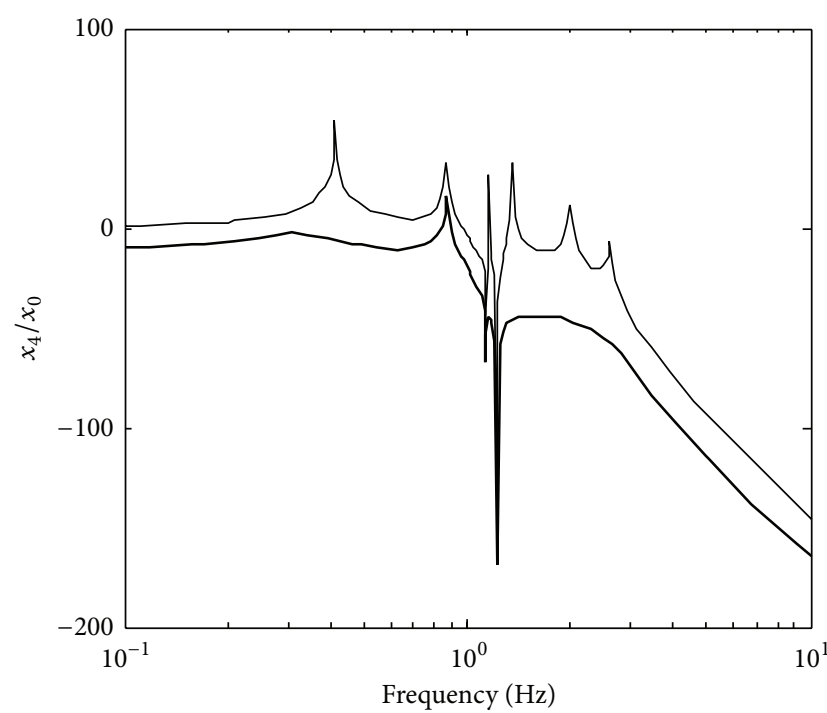

- Uncontrolled

- Controller 1

(a)

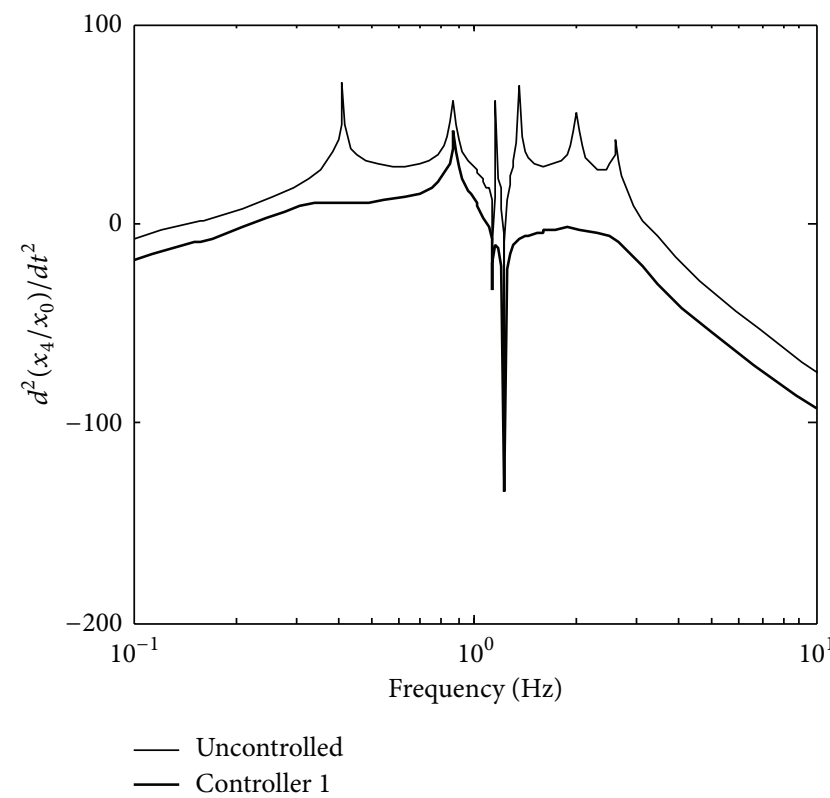

(b)

FIGURE 9: Controller 1 and uncontrolled cases frequency responses of $x_{4}$.

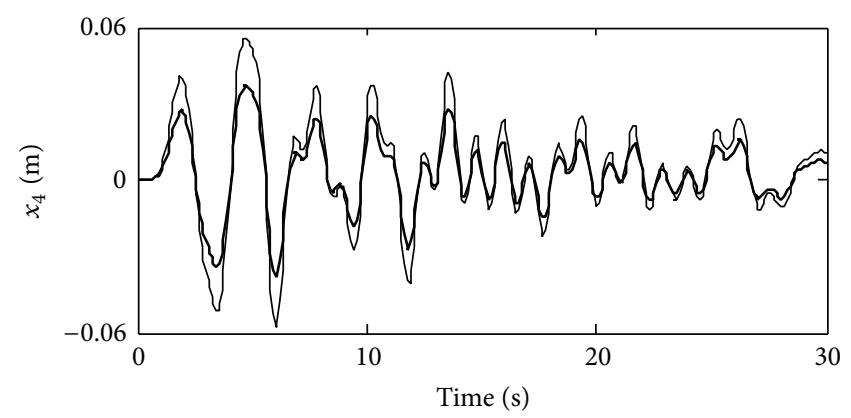

Controller 1

Controller 2

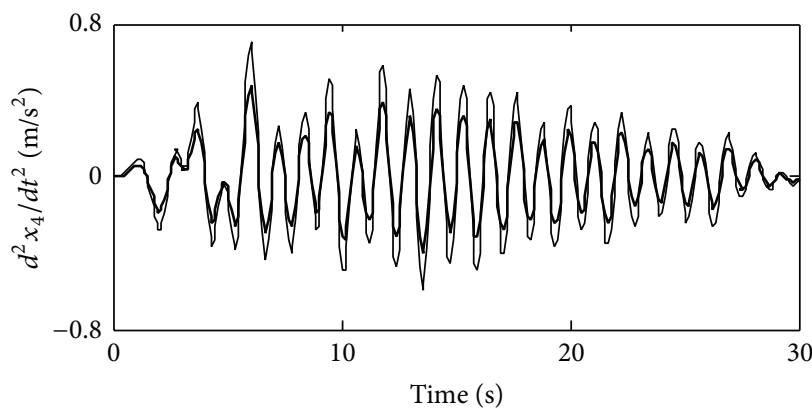

Controller 1

Controller 2

(a)

(b)

Figure 10: Comparison of time responses of the $x_{4}$ for controllers cases (El Centro earthquake). 


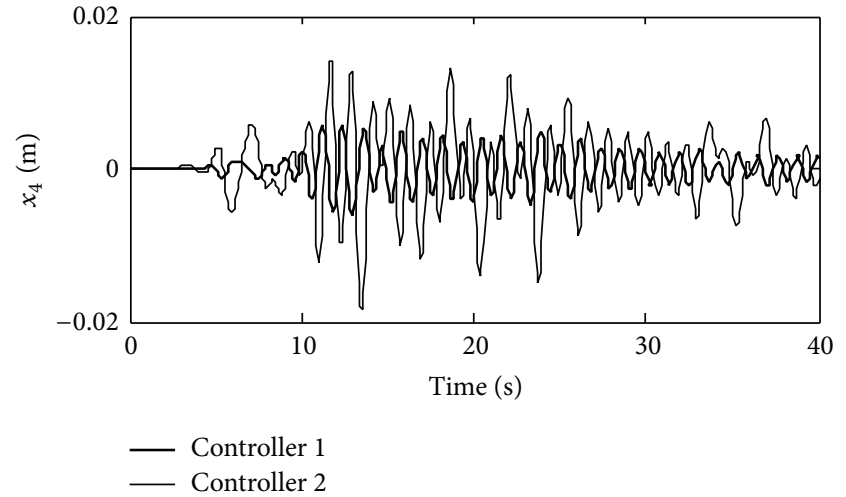

(a)

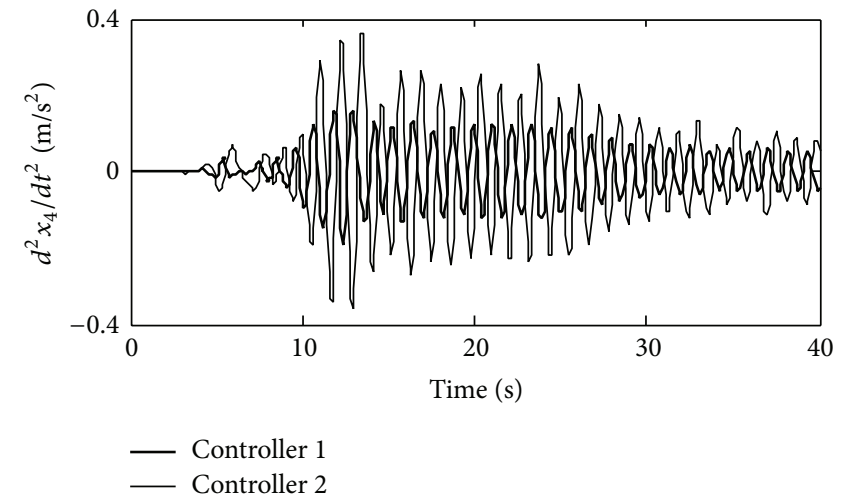

(b)

FIGURE 11: Comparison of time responses of the $x_{4}$ for controllers cases (Northridge earthquake).

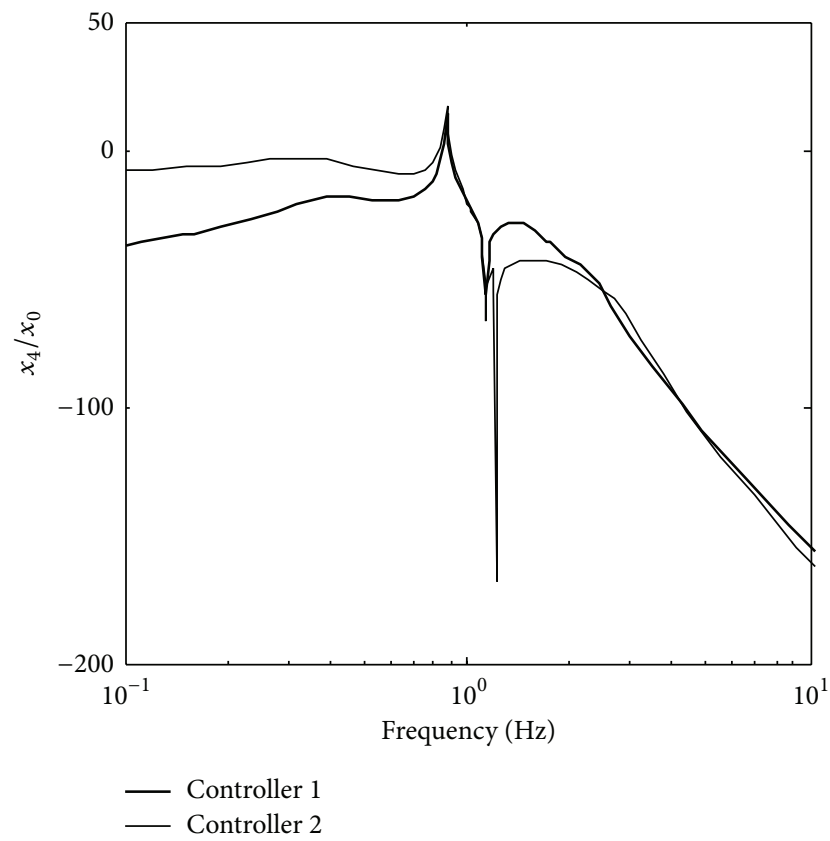

(a)

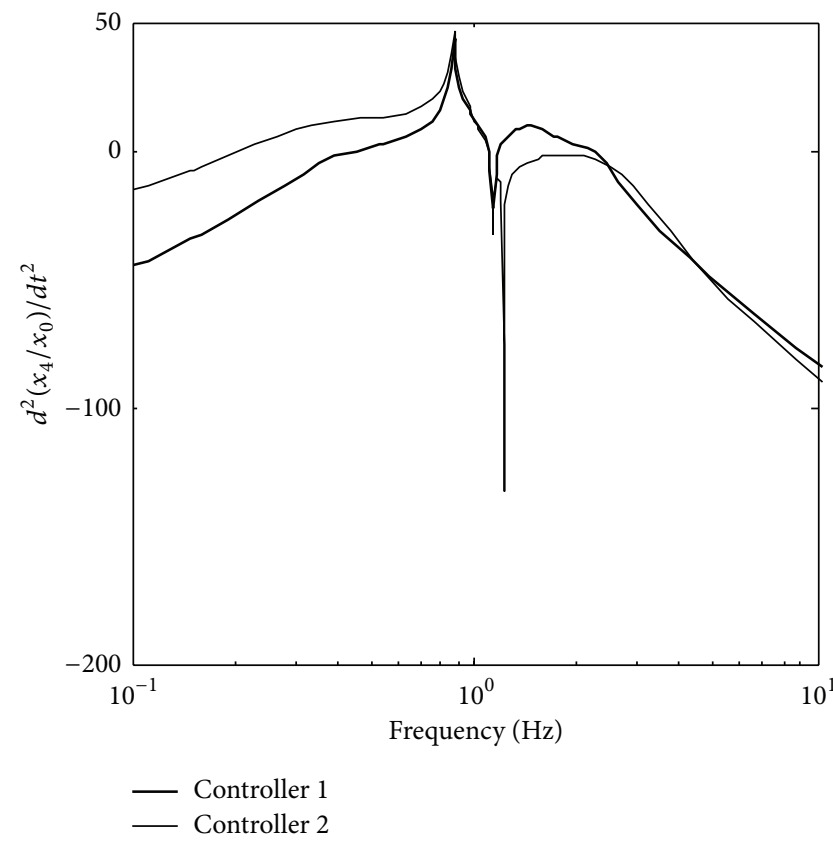

(b)

FIGURE 12: Comparison of frequency responses of the $x_{4}$.

frequency domain performance and does not guarantee good transient behaviors for the closed-loop system. To obtain desired frequency and transient response performance, $\mathrm{H}_{2}$ and $H_{\infty}$ controller objectives have combined as a mixed control problem by the use of LMIs. A six-degree-of-freedom container crane structure subject to seismic excitations is used to illustrate the effectiveness of the approach through simulations. Simulation results obtained by using real timehistory data of El Centro and Northridge earthquakes show that the proposed controller is very effective in reducing vibration amplitudes of crane parts. Comparison of the performance of the designed controller and a state-feedback $H_{\infty}$ controller revealed that responses of designed controller simulations give more successful results in the time and frequency domain. As a result, the proposed controller has great potential in active structural control for the seismic-excited container cranes which are under effect of disturbance inputs with unknown magnitude as earthquakes. The authors will study algorithm including time-delay, actuator saturation, and uncertainties to control structural vibration of cranes originating from earthquake excitations in the next studies.

\section{Appendix}

Parameters of the container crane system are shown in Table 1. 
TABLE 1

\begin{tabular}{|c|c|c|}
\hline$m_{1}=600$ ton & $c_{1}=26.17 \mathrm{kNs} / \mathrm{m}$ & $k_{1}=18050 \mathrm{kN} / \mathrm{m}$ \\
\hline$m_{2}=63$ ton & $c_{2}=10.68 \mathrm{kNs} / \mathrm{m}$ & $k_{2}=12448 \mathrm{kN} / \mathrm{m}$ \\
\hline$m_{3}=38.2$ ton & $c_{3}=1.9 \mathrm{kNs} / \mathrm{m}$ & $k_{3}=2210 \mathrm{kN} / \mathrm{m}$ \\
\hline$m_{4}=105$ ton & $c_{4}=2.89 \mathrm{kNs} / \mathrm{m}$ & $k_{4}=3360 \mathrm{kN} / \mathrm{m}$ \\
\hline$m_{5}=15$ ton & $c_{5}=0.65 \mathrm{kNs} / \mathrm{m}$ & $k_{5}=765 \mathrm{kN} / \mathrm{m}$ \\
\hline$m_{6}=20$ ton & $L=6 \mathrm{~m}$ & \\
\hline
\end{tabular}

The state-space matrices of the closed-loop system are as follows:

$$
\begin{gathered}
A=\left[\begin{array}{cc}
0 & I \\
-M_{s}^{-1} K_{s} & -M_{s}^{-1} C_{s}
\end{array}\right], \quad B_{h}=\left[\begin{array}{c}
0 \\
M_{s}^{-1} F_{u}
\end{array}\right], \\
B_{w}=\left[\begin{array}{c}
0 \\
M_{s}^{-1} E
\end{array}\right] .
\end{gathered}
$$

State vector, disturbance input vector, control input vector, and control output vector are as follows:

$$
\begin{aligned}
& x=\left[\begin{array}{llllllllllll}
x_{1} & x_{2} & x_{3} & x_{4} & x_{5} & \theta & \dot{x}_{1} & \dot{x}_{2} & \dot{x}_{3} & \dot{x}_{4} & \dot{x}_{5} & \dot{\theta}
\end{array}\right]^{T}, \\
& w=\left[\begin{array}{ll}
x_{0} & \dot{x}_{0}
\end{array}\right]^{T}, \\
& u=\left[\begin{array}{ll}
u_{1} & u_{2}
\end{array}\right]^{T} \text {, } \\
& z_{1}=z_{2}=\left[\begin{array}{llllllllllll}
x_{1} & x_{2} & x_{3} & x_{4} & x_{5} & \theta & \dot{x}_{1} & \dot{x}_{2} & \dot{x}_{3} & \dot{x}_{4} & \dot{x}_{5} & \dot{\theta}
\end{array}\right]^{T} \text {. }
\end{aligned}
$$

\section{Conflict of Interests}

The authors declare that there is no conflict of interests regarding the publication of this paper.

\section{Acknowledgments}

The authors would like to thank the editor and reviewers for their valuable comments and suggestions.

\section{References}

[1] S. Iai, "Port structures," in Earthquake Engineering Handbook, C. Scawthorn and W. Chen, Eds., New Directions in Civil Engineering, chapter 27, CRC Press, Boca Raton, Fla, USA, 2003.

[2] T. Kanayama and A. Kashiwazaki, "A study on the dynamic behavior of container cranes under strong earthquakes," Seismic Engineering, vol. 364, pp. 276-284, 1998.

[3] T. Kanayama, A. Kashiwazki, N. Shimizu, I. Nakamaura, and N. Kobayashi, "Large shaking table test of a container crane by strong ground excitation," Seismic Engineering, vol. 364, pp. 243-248, 1998.

[4] E. Soderberg and M. Jordan, "Seismic response of jumbo container cranes and design recommendations to limit damage and prevent collapse," in Proceedings of the ASCE Ports Conference, pp. 1-10, San Diego, Calif, USA, 2007.
[5] A. Sagirli, C. O. Azeloglu, R. Guclu, and H. Yazici, "Self-tuning fuzzy logic control of crane structures against earthquake induced vibration," Nonlinear Dynamics, vol. 64, no. 4, pp. 375384, 2011.

[6] A. Sagirli and C. O. Azeloglu, "Investigation of the dynamic behaviors of cranes under seismic effects with theoretical and experimental study," Advanced Materials Research, vol. 445, pp. 1082-1087, 2012.

[7] W. Sun, H. R. Karimi, S. Yin, and J. M. Rossell, "Active vibration control in mechanical systems," Mathematical Problems in Engineering, vol. 2014, Article ID 275087, 2 pages, 2014.

[8] W. Sun, Y. Zhao, J. Li, L. Zhang, and H. Gao, "Active suspension control with frequency band constraints and actuator input delay," IEEE Transactions on Industrial Electronics, vol. 59, no. 1, pp. 530-537, 2012.

[9] H. Gao, Y. Zhao, and W. Sun, "Input-delayed control of uncertain seat suspension systems with human-body model," IEEE Transactions on Control Systems Technology, vol. 18, no. 3, pp. 591-601, 2010.

[10] Y. Zhao, W. Sun, and H. Gao, "Robust control synthesis for seat suspension systems with actuator saturation and time-varying input delay," Journal of Sound and Vibration, vol. 329, no. 21, pp. 4335-4353, 2010.

[11] A. K. Agrawal and J. N. Yang, "Effect of fixed time delay on stability and performance of actively controlled civil engineering structures," Earthquake Engineering and Structural Dynamics, vol. 26, no. 11, pp. 1169-1185, 1997.

[12] H. Du and N. Zhang, " $H_{\infty}$ control for buildings with time delay in control via linear matrix inequalities and genetic algorithms," Engineering Structures, vol. 30, no. 1, pp. 81-92, 2008.

[13] W. Sun, Z. Zhao, and H. Gao, "Saturated adaptive robust control for active suspension systems," IEEE Transactions on Industrial Electronics, vol. 60, no. 9, pp. 3889-3896, 2013.

[14] J.-H. Kim, F. Jabbari, and Y. N. Yang, "Actuator saturation and control design for buildings under seismic excitation," in Proceedings of the American Control Conference, pp. 29-33, Chicago, Ill, USA, June 2000.

[15] H. Pan, Y. Zhang, and W. Sun, "Robust tracking control for vehicle lateral dynamics with uncertain parameters and external nonlinearities," Shock and Vibration, vol. 2014, Article ID 324018, 12 pages, 2014.

[16] S. G. Wang, H. Y. Yeh, and P. N. Roschke, "Robust control for structural systems with parametric and unstructured uncertainties," Journal of Vibration and Control, vol. 7, no. 5, pp. 753772, 2001.

[17] G. Song, J. Lin, Y. Zhao, W. P. Howson, and F. W. Williams, "Robust $H_{\infty}$ control for aseismic structures with uncertainties in model parameters," Earthquake Engineering and Engineering Vibration, vol. 6, no. 4, pp. 409-416, 2007.

[18] C. O. Azeloglu, A. Sagirli, and A. Edincliler, "Mathematical modelling of the container cranes under seismic loading and proving by shake table," Nonlinear Dynamics, vol. 73, no. 1-2, pp. 143-154, 2013.

[19] C. O. Azeloglu, A. Edincliler, and A. Sagirli, "Investigation of seismic behavior of container crane structures by shake table tests and mathematical modeling," Shock and Vibration, vol. 2014, Article ID 682647, 9 pages, 2014.

[20] N. Kobayashi, H. Kuribara, T. Honda, and M. Watanabe, "Nonlinear seismic responses of container cranes including the contact problem between wheels and rails," Journal of Pressure Vessel Technology, vol. 126, no. 1, pp. 59-65, 2004. 
[21] B. A. Francis, A Course in $H_{\infty}$ Control Theory, vol. 88 of Lecture Notes in Control and Information Sciences, Springer, Berlin, Germany, 1987.

[22] J. C. Doyle, K. Glover, P. P. Khargonekar, and B. A. Francis, "State-space solutions to standard $\mathrm{H}_{2}$ and $H_{\infty}$ control problems," IEEE Transactions on Automatic Control, vol. 34, no. 8, pp. 831-847, 1989.

[23] M. Chilali, P. Gahinet, and C. Scherer, "Multi-objective outputfeedback control via LMI optimization," in Proceedings of the IFAC 13th Triennial World Congress, San Francisco, Calif, USA, 1996.

[24] P. Gahinet and P. Apkarian, "A linear matrix inequality approach to $H_{\infty}$ control," International Journal of Robust and Nonlinear Control, vol. 4, no. 4, pp. 421-448, 1994.

[25] P. P. Khargonekar and M. A. Rotea, "Mixed $H_{2} / H_{\infty}$ control: a convex optimization approach," IEEE Transactions on Automatic Control, vol. 36, no. 7, pp. 824-837, 1991.

[26] J. Löfberg, "YALMIP: a toolbox for modeling and optimization in MATLAB," in Proceedings of the IEEE International Symposium on Computer Aided Control System Design (CACSD '04), pp. 284-289, IEEE, Taipei, Taiwan, September 2004.

[27] S. Boyd, L. El Ghaoui, E. Feron, and V. Balakrishnan, Linear Matrix Inequalities in System and Control Theory, vol. 15 of SIAM Studies in Applied Mathematics, Society for Industrial and Applied Mathematics (SIAM), Philadelphia, Pa, USA, 1994.

[28] A. A. Kasimzade, Structural Dynamics, Birsen Publication, Istanbul, Turkey, 2004.

[29] C. O. Azeloglu, Modeling of the behaviors of cranes under seismic effect and vibrations active control [Ph.D. thesis], Yildiz Technical University, Istanbul, Turkey, 2012. 

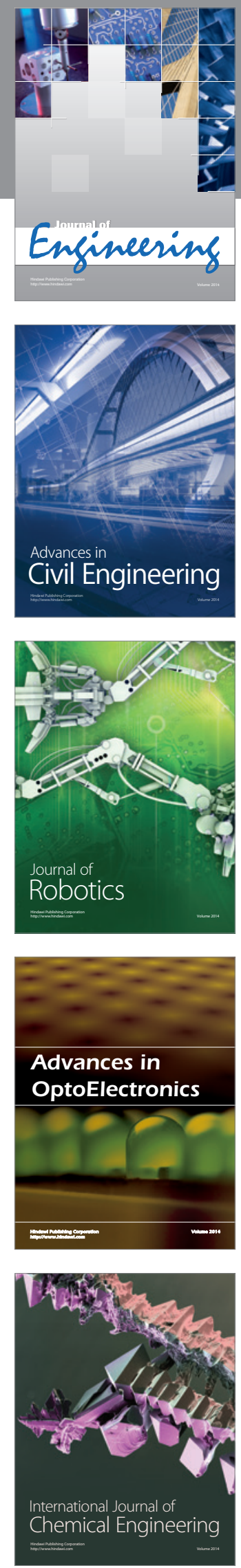

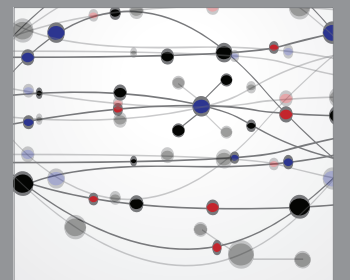

The Scientific World Journal
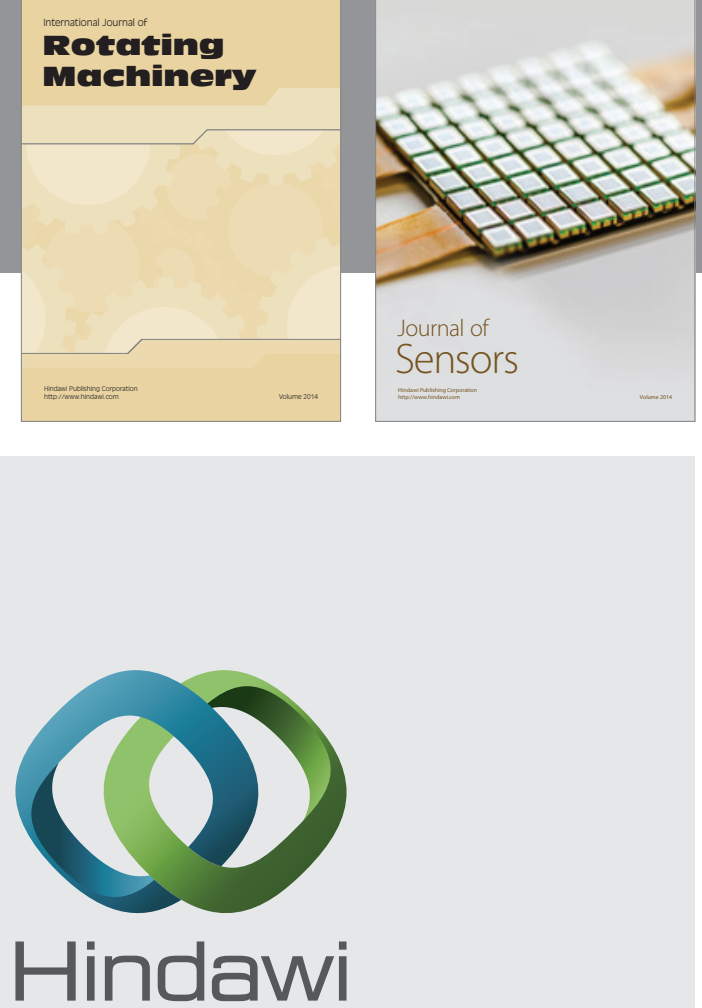

Submit your manuscripts at http://www.hindawi.com
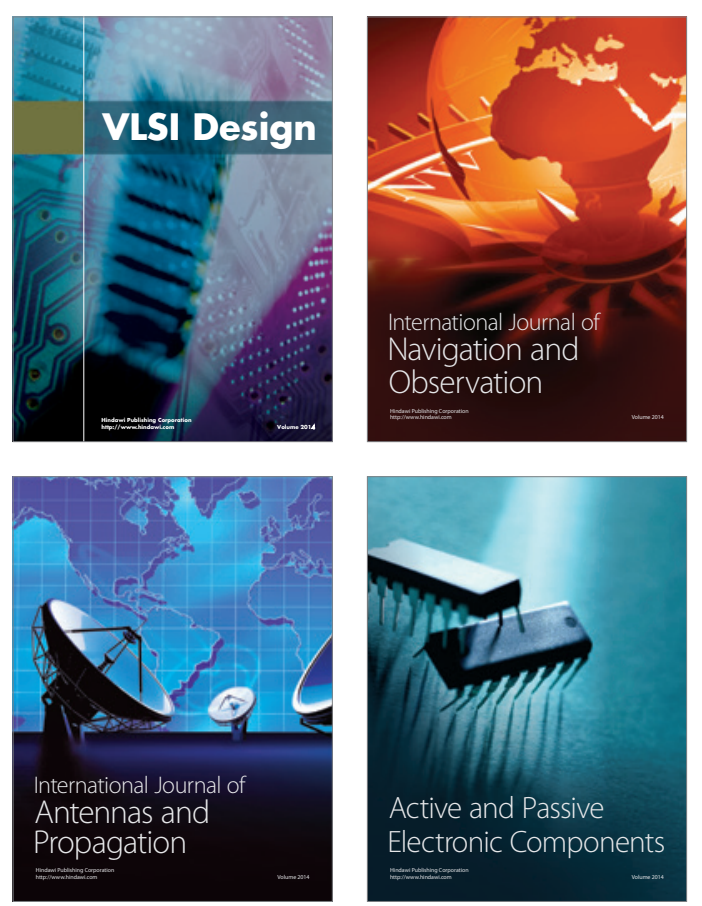
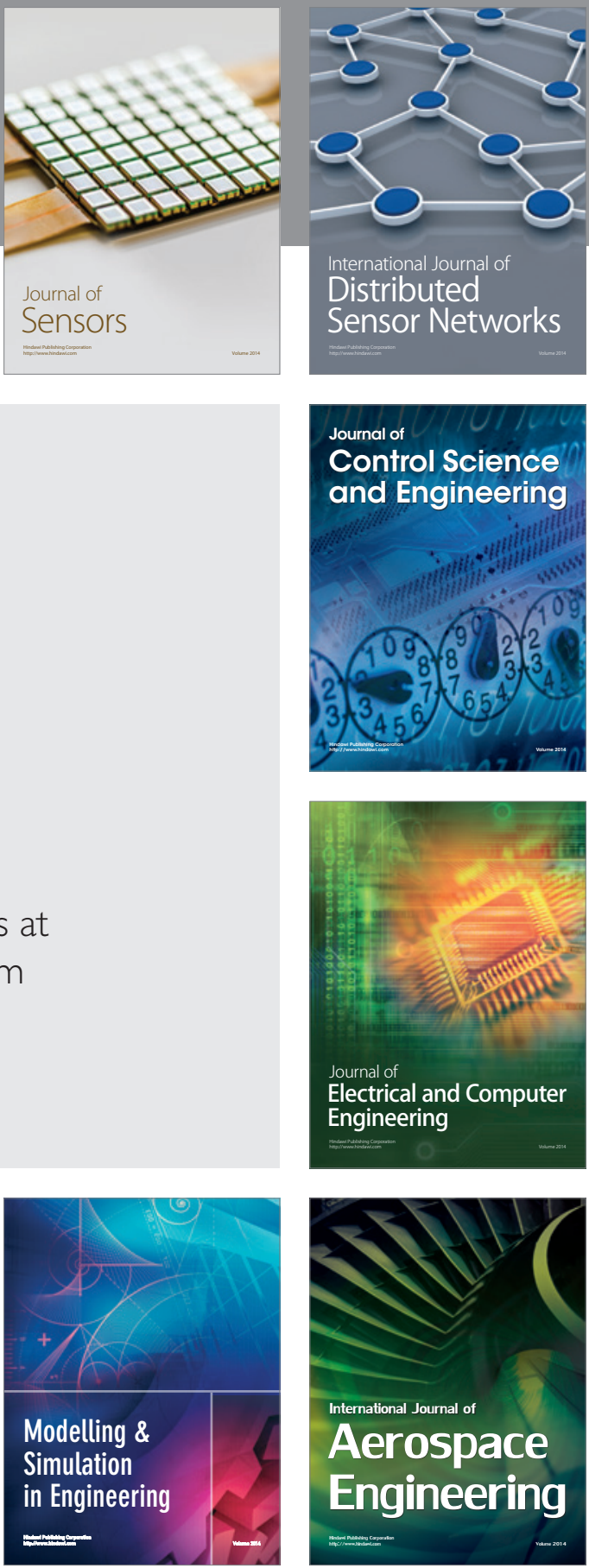

Journal of

Control Science

and Engineering
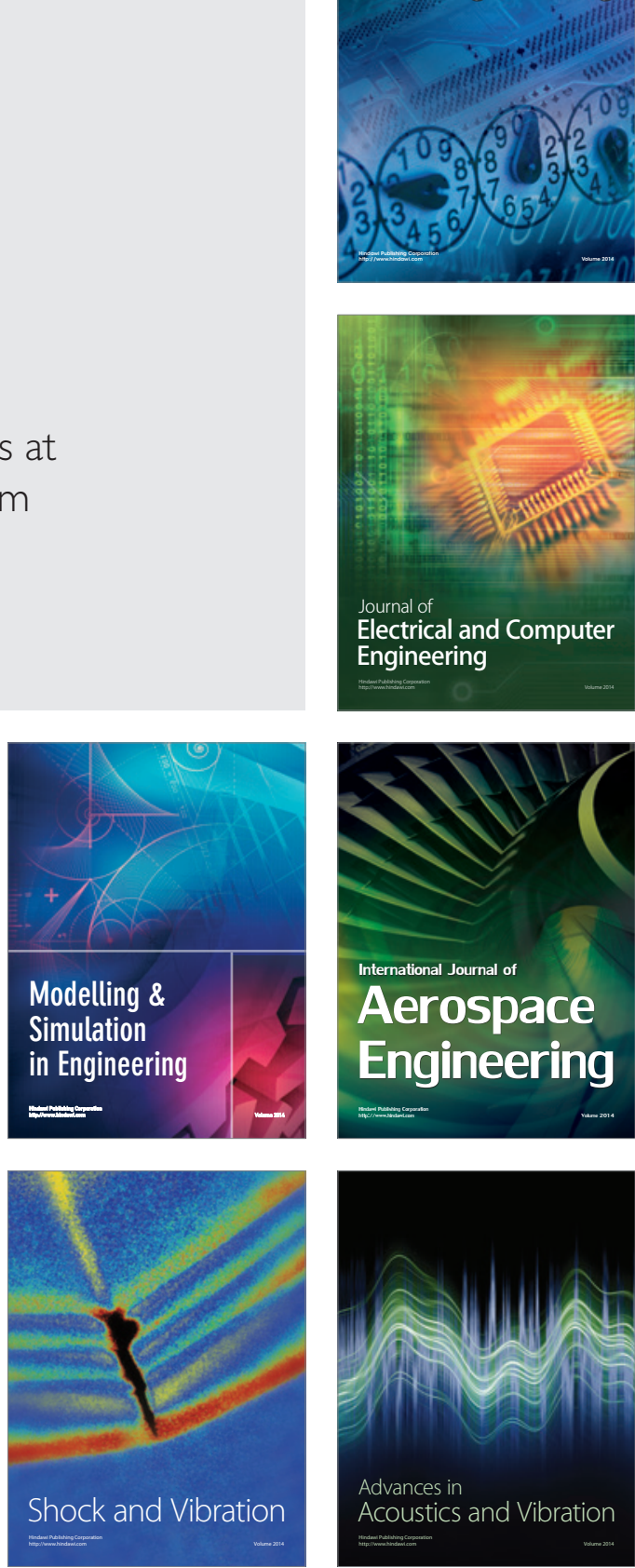